\title{
Epidemiology of dental caries: when structure and context matter ${ }^{*}$
}

\section{Paulo Frazão}

Departamento de Prática de Saúde Pública, Faculdade de Saúde Pública, Univ de São Paulo - USP, São Paulo, SP, Brazil.
* Paper presented at the "Oral Health Under an Integrality Perspective" International Symposium, held at the $17^{\text {th }}$ Congress of the Brazilian Association for Oral Health Promotion (ABOPREV), May 31 to June 2, 2012, Salvador, BA, Brazil.

Declaration of Interests: The author certifies that he has no commercial or associative interest that represents a conflict of interest in connection with the manuscript.

\section{Corresponding Author:}

Paulo Frazão

E-mail:pafrazao@usp.br

Submitted: Aug 09, 2012

Accepted for publication: Oct 02, 2012

Last revision: Oct 23, 2012
Abstract: The widespread expansion of the sugar market drove dental caries prevalence to high levels in several regions of the world. On the other hand, the dissemination of fluoride use is one of the reasons for caries decline at the end of the $20^{\text {th }}$ century. However, caries remains one of the most prevalent non-communicable chronic diseases in human beings, and an important cause of pain and dental loss, which lead to school and work absenteeism affecting individuals' daily activities and emotional stability. The decline in caries has important implications for research, human resources and oral healthcare. The aim of this study was to summarize the changes in dental caries occurrence in the population, and bring to light the latest research on the role of non-biological determinants in caries distribution.

Descriptors: Dental Caries; Epidemiology; Risk Factors.

\section{Introduction}

Dental caries is a multifactorial disease in which the signs of carious demineralization can be seen on the hard dental tissues, but the disease process is initiated within the bacterial biofilm (dental plaque) that covers the tooth surface. It is affected by the consumption of dietary sugars, salivary flow and composition, teeth cleaning and exposure to fluoride, ${ }^{1}$ among other factors. The health-disease process may be investigated on at least three levels: sub-individual, individual and population. ${ }^{2}$ In this last level, the chronic forms of dental caries predominate. The acute forms, characterized by periods of latency and short-term asymptomatic courses, occur in a small proportion of those affected by the disease, especially during the stage of tooth emergence in childhood. Although the vertical transmission of microorganisms associated with the occurrence of this disease from parents and caregivers to children has been demonstrated, from the point of view of the population, dental caries is not considered a communicable disease, and is recognized as part of the noncommunicable chronic diseases that best fit the research and description model.

Despite the decline in the population, the disease is still the main oral health problem in most industrialized countries and the major cause of tooth loss and pain leading to absenteeism at work and school, thus affecting the daily performance and emotional stability of individuals. ${ }^{3}$ The main objectives of dental caries epidemiology are to describe its distribution, to investigate its determining factors and to assess the impact of 
certain actions on its occurrence in the population.

The purpose of this article was to summarize the changes in occurrence of dental caries, highlighting the importance of non-biological determinants on its distribution in the population.

\section{Distribution of dental caries in the population}

Historical findings have shown that tooth decay emerged as an important disease in the population, as the process of urbanization and industrialization progressed in different regions of the planet. In Greece, where there are historical documents covering a long period, it has been possible to compare the attack of caries detected in the skeletons of individuals who lived thousands of years ago with the skeletons of newer individuals. The data shows a rapid deterioration during the $19^{\text {th }}$ century. The expansion of sugar consumption in the $16^{\text {th }}$ and $17^{\text {th }}$ centuries helps explain the change in the global scenario and the epidemic levels in more developed regions. ${ }^{4}$

The greater levels of caries and the growing perception of illness turned this oral health problem into a priority on the agenda of public health authorities. ${ }^{4}$ During World War I, one of the main reasons that young people were refused enlistment in the army was their bad mouth conditions. In the early 1930s, researchers in the public health service of the United States of America began to develop measurement techniques for monitoring distribution trends. Over the years, the DMFT index became a relevant tool for dental specialists. ${ }^{4}$ In spite of certain variations in the criteria for detecting its occurrence, the epidemiological information that was produced-based on tactile-visual examination and on the dentin lesion-allowed the first global comparisons to be made.

The publication of the first country maps identifying the classes of comparable DMFT values indicated a complex framework in the mid 1970s. Despite the predominance of high levels for most countries, ${ }^{5}$ the data showed that caries was increasing in some less developed regions and decreasing in some more developed regions. ${ }^{6}$

An unprecedented fact was recognized in 1982: the decline of dental caries in children and adolescents in some industrialized countries. The most important hypotheses were broad socioeconomic development and the spread of fluoride methods, including the fluoridation of vehicles such as water, salt, and toothpaste. ${ }^{7}$ Dental clinical services would explain less than $5 \%$ of the variation in the values observed. In addition to this change, there was an important polarization process described in the distribution of the disease burden, in which $70 \%$ to $80 \%$ of the carious lesions were reported to affect $20 \%$ to $30 \%$ of individuals. ${ }^{8}$ Currently, the WHO Global Oral Health Program supports a collaborating center at Malmö University (Sweden) that gathers and provides caries prevalence data for oral health surveillance (http://www.mah.se/capp/). A synthesis of the broad epidemiological pattern in the early $21^{\text {st }}$ century shows that the prevalence of edentulism is often higher and the mean number of retained teeth is therefore markedly lower among populations in high-income countries, as compared with low- and middle-income countries.

The decline in caries in Brazilian children was first observed in the mid 1990s, according to two epidemiological surveys covering different parts of the country. ${ }^{9}$ A reduction in the severity levels of the disease was identified in adolescents and adults in 2003. A concentration of the greatest disease burden was also observed in a small proportion of individuals. ${ }^{10}$ The expansion of the water fluoridation program in the 1980s has prevailed among the possible explanations for the decline in Brazil. ${ }^{9,10}$ From an economic point of view, fluoridation expansion as a public policy was driven by federal funding, and, from a political perspective, by decision of the state governors, who were again elected by direct vote in 1982, after Brazil's return to democracy. Another measure to be considered was the addition of fluoride to the most marketed toothpaste brands and the spread of its daily use in elementary schools after approval of federal funding for the development of school-based topical fluoride programs. ${ }^{9,10}$ Also worth mentioning are the public policies of social protection and economic adjustment.

Brazil has seen an improvement in human development since the last decade of the $20^{\text {th }}$ century. 
In recent years, the income inequality measured by the Gini index fell to its lowest levels in fifty years (0.53). One of the most visible consequences has been the population mobility among different income and educational levels. A reduction was seen in the number of families that lived with a per capita income of up to half of a minimum wage. On the other hand, an increase in teenage and adult schooling was noticed. Evidence from different studies has supported the correlation between human development and dental caries. ${ }^{11-13}$

\section{Implications of dental caries decline}

The decline of caries prevalence has important implications on research, as well as on the training and development of the workforce, and the management of health systems and dental services. From the point of view of research, the asymmetric distribution of caries disease implied that new forms of analysis and comparison of its occurrence had to be devised within and between populations. In addition, the investigation of changes in dental caries patterns allowed the formulation of five postulates by which it is possible to predict (1) the average levels of DMFT in older ages based on current levels, if environmental conditions are stable and there is no effective intervention; (2) the average level of DMFT and the percentage of caries-free children; (3) the average values of DMFS from the DMFT and vice versa; (4) the most affected surfaces and tooth groups according to the level of DMFT at a given period of time; (5) and the rate of caries progression. ${ }^{14}$

The caries decline implies a greater number of teeth retained for future generations. The maintenance of current low levels and the search for future gains will require more emphasis on contents and practices addressing health promotion and disease prevention for developing the upper and middle level workforce. A balance between generalists and specialists suited to deal with the oral health needs of each population should be sought, combined with efforts to increase the diversity, capacity, and flexibility of the workforce.

In relation to the community-based programs and oral healthcare services within health systems, it is important to pursue current efforts toward reforming the health sector, and improving its funding and management for universal coverage, comprehensiveness and equity of care. ${ }^{15}$ Systems for monitoring, surveillance and evaluation of populationwide strategies related to fluoridated water, salt and toothpastes must be maintained. In addition, it is important to improve the community-based oral health programs on caries prevention among children $^{16}$ and teenagers in order to redirect the activities undertaken by upper level professionals toward other population groups.

\section{When structure and context matter}

In the past, when the disease affected virtually the entire population, the Keyes' diagram ${ }^{17}$ was the predominant explanation model among scholars. Due to concentration of the disease burden on a small proportion of the population, growing interest has been directed to the study of non-biological determinants and other aspects that transcend the individual level.

Several studies, using variables relating to schooling and income of the individual, parents or family, have shown a higher prevalence and severity of tooth decay among population groups located in the lower levels of socioeconomic classes. This association has been attributed to a lack of access to fluoride and the very frequent consumption of sugary foods and drinks to which these groups are exposed, ${ }^{18,19}$ among other reasons.

However, the role of sugar may not be as important as it was in the past, before the population was exposed to multiple sources of fluorides. ${ }^{20}$ In recent years, changes have been observed in the social context of eating. The family meal has been replaced by a more irregular and solitary eating habit. This habit not only increases consumption frequency but also confuses food functions. Items that traditionally were part of the main meal and did not represent a risk to teeth became a snack item that could turn into a dental health menace. ${ }^{21}$ The supply and the consumption of carbonated drinks and juices 
are becoming increasingly more frequent. ${ }^{18}$ Changes in food contents-a greater offer of products of varied composition, in which certain ingredients are not labeled and may even be masked in their general composition-may also represent risks to oral health. This is the case of pure starch-based foods, compared to those based on a mixture of sugar and starch, ${ }^{22}$ considering that the latter composition may be more cariogenic than the effect of sucrose. ${ }^{23}$

Studies in the United Kingdom have shown that water fluoridation may reduce social inequalities in caries experience, in both deciduous and permanent teeth. ${ }^{24,25}$ The notion that water fluoridation is an environmental variable that would not be affected by the position of individuals in the social structure or by income and educational levels ${ }^{26}$ would require that it be distributed equally, without any important variation related to consumption sources or fluid intake frequency in different population groups; however, this cannot always be ensured. ${ }^{27}$ The implementation of public policies may vary in extent and depth according to the structure of each country. Because water fluoridation is an oral health policy, it may express inequalities related to the implementation of public health policies ${ }^{28}$ and works as a marker for sociodental inequalities. ${ }^{29}$ One of the reasons for the small impact of salt fluoridation programs in Eastern Europe after the fall of the Berlin Wall has been the absence of a public policy to ensure affordable prices in relation to conventional products. ${ }^{30}$

In terms of social structure, several studies have shown the association between dental caries and income inequality. ${ }^{13,31-33}$ A plausible explanation is that high income inequality could be associated with under-investment in public policy, including the delivery of health services. Relationships of this type were investigated in Brazil, and income inequality lost significance following adjustments for a scale of public policies and years of water fluoridation. Public policies explained most of the variation in missing and decayed teeth. ${ }^{34}$ In another study on the effect of a public policy that ensured community-based oral health programs, untreated caries prevalence was higher in municipalities where the rate per inhabitant of preventive care was lower. ${ }^{35}$
Another possible explanation relates to behavioral factors. Behaviors such as smoking, dietary habits, physical activity and alcohol consumption could account for health-related social inequalities. However, little is known about the role of behavioral factors in oral-health-related social inequalities. One hypothesis is that diet (sugar consumption) and oral hygiene (with fluoridated toothpaste) could change under stressful situations. Certain occupations or social positions may lead to conditions like low selfworth and strain, anxiety, shame, hostility and depression, which could be associated to behavioral changes and vulnerability of groups and individuals.

In addition to the relationship of income inequality to under-investment in public policy, there could be at least two potential pathways to investigate the psychosocial explanation for income inequality, one being social capital (e.g. measured as social cohesiveness and discrimination), and the other being stress-induced behavior. The first may bear reference on a contextual level, and the second, on an individual level. ${ }^{36}$

A study assessed the association between family affluence as a proxy of socioeconomic status and oral health-related behaviors in adolescents, including such influences as pocket money, type of school, family structure and psychological factors. The researchers found a linear association with health-enhancing behaviors (toothbrushing and dentist visits), and a roughly U-shaped association with healthcompromising behaviors (current smoking, drinking soft drinks and eating confectionaries). After adjusting for a number of variables, the linear association with health-enhancing behaviors persisted. The U-shaped association with health-compromising behaviors remained but was partly attenuated and flattened. Pocket money and not living with both parents modified the magnitude of the association between familiar affluence and oral-health-compromising behaviors. The findings indicated that the health-enhancing behaviors of adolescents were strongly associated with a proxy of socioeconomic status, but the health-compromising behaviors were more strongly linked to factors other than family affluence. ${ }^{37}$

Regardless of the situation, the fact is that we 
know little about how factors such as the education system, peer group, youth culture, part-time work and advertising contribute to family affluence. Further studies are needed to assess characteristics that interact with family socioeconomic status to better understand the association between socioeconomic status and the oral health-compromising behaviors of adolescents.

Studies need to be directed towards understanding the factors that determine behaviors and the social context in which behavioral choices are made. There is a need to move away from the notion that individual choices are responsible for "bad behavior" and to understand the social factors that influence behavioral decisions. A social and cultural perspective regarding behavioral decision-making is still largely absent from the health inequalities literature. ${ }^{26}$ A study was conducted on dental caries that investigated the influence of family socioeconomic trajectories and associated behaviors in Brazilians aged 15 years old, under the life course theory. It showed that poverty in early life has an effect on dental caries, oral behaviors and use of dental services later on, mitigated only partially by upward social mobility between childhood and adolescence. ${ }^{38}$

\section{Final remarks}

Over forty years after the Keyes' diagram was formulated, it is now time to advance beyond the Keyes model, ${ }^{16}$ according to which the etiology of caries was thought of as a genuinely biological process. In a causal perspective, this approach has represented a misleading limitation. Family factors and aspects related to the community context and social structure have become recognized as important dimensions of the dental caries causal complex. ${ }^{39,40}$

Even an improved understanding of the biological processes at work on the tooth surface cannot explain caries occurrence within and between populations. The etiology of caries in populations presumably comprises elements from both natural and social science tradition and theories. Building theories across these two scientific traditions has proven difficult. If at all possible, a theory of caries across populations should have the potential of bridging societal, individual and biological elements. ${ }^{39}$

As Holst ${ }^{39}$ stated, it urges to extend the concept of causation of caries to comprise also non-biological variables that, in a series of steps, ultimately lead to caries. In light of currently produced knowledge, determinants and factors more distant than biology should not be considered as confounders of causal relationships.

In the early $21^{\text {st }}$ century, a significant bulk of evidence allows us to assume that social, economic, cultural, environmental and health-system-related determinants are part of a web of possible causes of dental caries. It follows then that understanding these determinants deserves more attention by researchers, if they search really to understand the distribution of caries in the population. Although it may be difficult to separate these determinants, they are probably not on the same level. The social structure may comprise aspects related to public policies of social protection and economic adjustment that emerge as income inequality and unequal access to community-based oral health programs and clinical services. These may, in turn, affect the population's social context, such as its neighborhood, local organizations and family, work or school environment, which have implications related to individual material resources, literacy and behaviors. Moreover, all of these are related to fluoride exposure, oral hygiene and sugar consumption, which will affect the occurrence of caries and its rate of progression.

However, these determinants are related to each other on the same level and to other determinants on different levels, seeing that they may function reciprocally. For example, reductions in income inequality provide public support for increases in systems that distribute resources in an equitable manner, and the equitable distribution of resources, in turn, may reduce levels of socioeconomic inequality. An urgent task facing researchers is to establish the importance of each determinant and their interconnections with the causal complex of dental caries. 


\section{References}

1. Selwitz HR, Ismail A, Pitts BN. Dental caries. Lancet. 2007 Jan;369(9555):51-9.

2. Almeida-Filho N. For a general theory of health: preliminary epistemological and anthropological notes. Cad. Saude Publica. 2001 Jul-Ago;17(4):753-70.

3. Sheiham, A. Oral health, general health and quality of life. Bull World Health Organ. 2005 Sep;83(9):644.

4. Narvai PC, Frazão P. Saúde bucal no Brasil: muito além do céu da boca. Rio de Janeiro: Fiocruz; 2008.

5. Barmes DE. Global problems of oral diseases. Br Dent J. 1979 Jan 2;146(1):21-4.

6. Ericsson Y. Progress in caries prevention. Caries Res. 1978;12(S1):1-2. Preface.

7. Petersson HG, Bratthall D. The caries decline: a review of reviews. Eur J Oral Sci. 1996 Aug;104(4):436-43

8. Kaste LM, Selwitz RH, Oldakowski RJ, Brunelle JA, Winn DM, Brown LJ. Coronal caries in the primary and permanent dentition of children and adolescents 1-17 years of age: United States, 1988-1991. J Dent Res. 1996 Feb;75(Spec Iss):631-41.

9. Narvai PC, Frazão P, Castellanos RA. Declínio na experiência de cárie em dentes permanentes de escolares brasileiros no final do século XX. Odontol Soc. 1999;1:25-9.

10. Narvai PC, Frazão P, Roncalli AG, Antunes JL. Cárie dentária no Brasil: declínio, polarização, desigualdade e exclusão social. Pan Am J Public Health. 2006 Jun;19(6):385-93.

11. Peres MA, Peres KG, Antunes JLF, Junqueira SR, Frazão P, Narvai PC. The association between socioeconomic development at the town level and the distribution of dental caries in Brazilian children. Rev Panam Salud Publica. 2003 Sep;14(3):149-57.

12. Frazão P, Antunes JLF, Narvai PC. [Early tooth loss in adults aged 35-44 years old. State of Sao Paulo, Brazil, 1998]. Rev Bras Epidemiol. 2003 Apr;6(1):49-57. Portuguese.

13. Baldani MH, Vasconcelos AGG, Antunes JLF. [Association of the DMFT índex with socioeconomic and dental services indicators in the state of Paraná, Brazil.] Cad Saúde Pública. 2004 Jan-Feb;20(1):143-52. Portuguese.

14. Sheiham A, Sabbah W. Using universal patterns of caries for planning and evaluating dental care. Caries Res. 2010 Apr;44(2):141-50.

15. Frazão P. 20 years of experience with the Brazilian Unified National Health System: strides and challenges for oral health. Cad Saude Publica. 2009 Apr;25(4): 712.

16. Frazão P. Effectiveness of the bucco-lingual technique within a school-based supervised toothbrushing program on preventing caries: a randomized controlled trial. BMC Oral Health. 2011 Mar 22;11:11.

17. Keyes PH. Present and future measures for dental caries control. J Am Dent Assoc. 1969 Dec;79(6):1395-404.

18. Sheiham A. Dietary effects on dental diseases. Public Health Nutr. 2001 Apr;4(2B):569-91.
19. Petersen PE, Lennon MA. Effective use of fluorides for the prevention of dental caries in the 21st century: the WHO approach. Community Dent Oral Epidemiol. 2004 Oct;32(5):319-21.

20. Burt BA, Pai S. Sugar consumption and caries risk: a systematic review. J Dent Educ. 2001 Oct;65(10):1017-23.

21. van Loveren CV, Duggal MS. Experts' opinions on the role of diet in caries prevention. Caries Res. 2004;38(S1):16-23.

22. Lingström P, van Houte J, Kaskhet S. Food starches and dental caries. Crit Rev Oral Biol Med. 2000;11(3):366-80.

23. Ribeiro CC, Tabchoury CP, Del Bel Cury AA, Tenuta LM, Rosalen PL, Cury JA. Effect of starch on the cariogenic potential of sucrose. Br J Nutr. 2005 Jul;94(1):44-50.

24. Riley J, Lennon M, Ellwood R. The effect of water fluoridation and social inequalities on dental caries in 5-year-old children. Int J Epidemiol. 1999 Apr;28(2):300-5.

25. Jones CM, Worthington $\mathrm{H}$. Water fluoridation, poverty and tooth decay in 12-year-old children. J Dent. 2000 Aug;28(6):389-93.

26. Sisson KL. Theoretical explanations for social inequalities in oral health. Community Dent Oral Epidemiol. 2007 Apr;35(2):81-8.

27. Sohn W, Noh H, Burt BA. Fluoride ingestion is related to fluid consumption patterns. J Public Health Dent. 2009 Fall;69(4):267-75.

28. Peres MA, Fernandes LS, Peres KG. Inequality of water fluoridation in Southern Brazil: the inverse equity hypothesis revisited. Soc Sci Med. 2004 Mar;58(6):1181-9.

29. Gabardo MC, Silva WJ, Moyses ST, Moyses SJ. Water fluoridation as a marker for sociodental inequalities. Community Dent Oral Epidemiol. 2008 Apr;36(2):103-7.

30. Marthaler TM. Changes in Dental Caries 1953-2003. Caries Res. 2004 May-Jun;38(3):173-81.

31. Antunes JL, Frazão P, Narvai PC, Bispo CM, Pegoretti T. Spatial analysis to identify differentials in dental needs by area-based measures. Community Dent Oral Epidemiol. 2002 Apr;30(2):133-42.

32. Pattussi MP, Marcenes W, Croucher R, Sheiham A. Social deprivation, income inequality, social cohesion and dental caries in Brazilian school children. Soc Sci Med. 2001 Oct;53(7):915-25.

33. Bernabe E, Sheiham A, Sabbah W. Income, income inequality, dental caries and dental care levels: an ecological study in rich countries. Caries Res. 2009;43(4):294-301.

34. Celeste RK, Nadanovsky P. How much of the income inequality effect can be explained by public policy? Evidence from oral health in Brazil. Health Policy. 2010 Oct;97(2-3):250-8.

35. Celeste RK, Nadanovsky P, Leon AP. [Association between preventive care provided in public dental services and caries prevalence]. Rev Saude Publica. 2007 Oct;41(5):830-8. Portuguese. 
36. Kawachi I, Kennedy BP. Income inequality and health: pathways and mechanisms. Health Serv Res.1999 Apr;34(1):21527.

37. Jung SH, Tsakos G, Sheiham A, Ryu JI, Watt RG. Socioeconomic status and oral health-related behaviors in Korean adolescents. Soc Sci Med. 2010 Jun;70(11):1780-8.

38. Peres MA, Peres KG, Barros AJD, Victora CG. The relation between family socioeconomic trajectories from childhood to adolescence and dental caries and associated oral behaviours. J Epidemiol Community Health. 2007 Feb;61(2):141-5.

39. Holst D, Schuller AA, Aleksejuniene J, Eriksen HM. Caries in populations: a theoretical, causal approach. Eur J Oral Sci. 2001 Jun:109(3):143-8.

40. Fisher-Owens SA, Gansky SA, Platt LJ, Weintraub JA, Soobader MJ, Bramlett MD, et al. Influences on children's oral health: a conceptual model. Pediatrics. 2007 Sep;120(3):e510-20. 